\title{
Penicillin Induced Lysis in Escherichia coli
}

\author{
BY H. G. BOMAN AND KERSTIN G. ERIKSSON \\ Institute of Biochemistry, University of Uppsala, Uppsala, Sreden
}

(Received 2 July 1962)

\begin{abstract}
SUMMARY
The paper is a survey of the action of $\alpha$-aminobenzylpenicillin (ampicillin) on Escherichia coli. The rate at which lysis was induced in exponentially growing organisms was studied for different concentrations of ampicillin, using pure $D$ - and $L$-forms as well as a 6:4 mixture. The interpolated concentration of penicillin which gives lysis in one generation, the 'LIOG value', has been used for characterization of penicillin derivatives with twelve different side chains. These LIOG values were also used for characterization of some penicillin-resistant mutants. The lysis rate has been recorded for cultures of concentrations between $4 \times 10^{5}$ and $10^{8} \mathrm{rods} / \mathrm{ml}$. and found to be independent of the population density. The use of five different media showed that for a given ampicillin concentration the time to lysis was proportional to the growth rate. The addition of penicillinase to a culture growing with penicillin rescued the organisms as late as a few minutes before lysis. Synergistic effects on the lysis rates were found with 6-aminopenicillanic acid and two amino acids, which as residues are side chains, in two of the penicillins tested. Different models for penicillin action in E. coli are discussed.
\end{abstract}

\section{INTRODUCTION}

Cell walls of Gram-negative bacteria are complex structures containing polysaccharides, lipids and protein-like material with a variety of amino acids some of which are D-isomers (see reviews by Salton, 1960a, $b$; Work, 1961). An organism like Escherichia coli can therefore be said to make two classes of polymerized amino acids: cell wall material and intracellular proteins. Several studies indicate that penicillin selectively inhibits the synthesis of wall material and that chloramphenicol or puromycin selectively block the synthesis of intracellular proteins (see reviews by Strominger, 1960; Novelli, 1960). Thus there may exist two pathways for the synthesis of polymerized amino acids, with a branching point somewhere between the amino acids and the ribosomal particles. The classical benzylpenicillin, penicillin G, shows a relatively poor antibiotic activity against Gram-negative bacteria such as $E$. coli. Rolinson \& Stevens (1961) have, however, recently described some properties of a new penicillin with a D-amino acid residue as side chain, $\alpha$-aminobenzylpenicillin (Penbritin; ampicillin), and this penicillin derivative has a rather high bactericidal effect against non-penicillinase producing $\boldsymbol{E}$. coli.

The present paper is mainly a survey of the action of ampicillin on Escherichia coli, measured as the induction of lysis. Some penicillin-resistant mutants have been isolated and characterized. Resistance to penicillin is in many cases related to the production of the enzyme penicillinase (see review by Pollock, 1959). It is therefore possible that the system will be suitable for combined genetic and biochemical 
studies. As an approach to the study of penicillinase action in vivo we have added purified penicillinase to sensitive cultures at different stages of penicillin action and can in this way prevent lysis. The recent isolation of 6-aminopenicillanic acid (Batchelor et al. 1959) has already led to the synthesis of several thousands of new penicillins (Abraham \& Newton, 1961) and this work has opened possibilities for a systematic study of the influence of the side chain of the penicillin molecule. We have in the present paper studied certain aspects of this problem with the cooperation of Dr B. Sjöberg, of the Astra Co. Södertälje, Sweden.

\section{METHODS}

Organism. Escherichia coli $\mathbf{\mathrm { K }} 12$, strain $\times 5$, was used in all experiments except where otherwise stated. Other strains used were mutants of strain $\times 5$ resistant to different concentrations of penicillin. Strain $\times 5$ was an $\boldsymbol{H} f r$ auxotroph requiring thiamine, arginine, and either methionine or cysteine. The parent strain $\left(30 S_{o} \arg 5\right)$ was obtained from Dr W. K. Maas. The methionine/cysteine marker was introduced by the conventional Davis-Lederberg technique as described by Lederberg (1950). The generation time of strain $\mathrm{x} 5$ in nutrient glucose medium (see below) was $30-40 \mathrm{~min}$.; in minimal medium with arginine or methionine about $60 \mathrm{~min}$.

Medium. The basal medium E according to Vogel \& Bonner (1956) was used in all but one experiment. It was normally supplemented with: thiamine, $1 \mu \mathrm{g} . / \mathrm{ml}$.; Difco nutrient broth, $0.8 \%$; glucose, $0.5 \%$. In minimal medium, nutrient broth was replaced with L-arginine, $25 \mu \mathrm{g} . / \mathrm{ml}$. and DL-methionine, $25 \mu \mathrm{g} . / \mathrm{ml}$. Casamino acids, agar, and nutrient agar were Difco standard products. In the preparation of plates with ampicillin, care was taken to minimize the time the ampicillin was heated, but some hydrolysis may nevertheless have occurred and given an error in the ampicillin concentration in the plates.

Growth conditions. An overnight culture was grown at $30^{\circ}$ without shaking. This culture was diluted in the morning with fresh medium and allowed to grow on a rotatory shaker at $37^{\circ}$ for $1 \frac{1}{2}-2 \mathrm{hr}$; ; it was checked that the organisms were growing at the expected rate. A sample (2-4 ml.) of this culture was used as inoculum and at zero time diluted with medium to $20 \mathrm{ml}$., by using $100 \mathrm{ml}$. flasks with side tube. Growth was normally followed with a Klett-Summerson photo-electric colorimeter, using filter no. 66 .

Materials. All penicillin derivatives were kindly obtained from Astra Co., Södertälje, Sweden. They have been numbered 1-14 and are listed in Table 2, which gives the formula of the side chains, purity data and our determinations for the lytic activity. The aminopenicillins (compounds 1-7) were synthesized as described by Ekström et al. (to be published) and compounds 9 and 11 according to Sjöberg \& Ekström (to be published). All other penicillin derivatives used were products commercially available, which had been subjected to further purifications by Dr Sjöberg's group. Three forms of ampicillin were used; the pure $\mathrm{D}$ - and L-isomers, and a mixture (designated SPC 270), containing about $60 \% \mathrm{D}$-isomer and $40 \% \mathrm{~L}$-isomer, resulting from an asymmetric synthesis. Concentrated solutions of penicillins were made up once a week and stored at $-18^{\circ}$. Solutions of the $L$-form of ampicillin were always freshly made. All concentrations given refer to the amount of penicillin analytically determined in each sample. The penicillinase used was from Bacillus cereus and is 
commercially available ('Neutrapen') from Scheen Pharmaceutical Corp., New York 1, N.Y., U.S.A. One unit of this penicillinase is defined as the amount of penicillinase which would inactivate one unit of penicillin per minute at $25^{\circ}$ and pH 7·0 (Levy, 1950).

Experiments with radioactive isotopes. Carrier free ${ }^{35} \mathrm{~S}$ sulphate with $0.67 \mu \mathrm{C}$. $/ \mu \mathrm{l}$. and uniformly labelled ${ }^{14} \mathrm{C}$ arginine with $5.9 \mathrm{mC}$. $/ \mathrm{m}$-mole were obtained from The Radiochemical Centre, Amersham, England. DL-methionine-2-14 C with 0.57 mC./ m-mole was obtained from California Corp. for Biochemical Research, Los Angeles 63, Calif., U.S.A. The sulphur-free medium of Roberts et al. (1957) was used, supplemented with glucose $(0.5 \%),{ }^{14} \mathrm{C}$ arginine and ${ }^{14} \mathrm{C}$-methionine $(0.06$ and $0.12 \mu$ mole/ $\mathrm{ml}$., respectively) and ${ }^{35} \mathrm{~S}$ sulphate $(0 \cdot 67 \mu \mathrm{C} / \mathrm{ml}$.). At the indicated times, samples ( $1 \mathrm{ml}$.) of culture were withdrawn and passed through filter Co 5 from Membranfilter (Göttingen, Germany). Each sample was washed with $10 \mathrm{ml}$. of a solution containing $0.01 \mathrm{M}-\mathrm{HCl}, 1 \%(\mathrm{w} / \mathrm{v})\left(\mathrm{NH}_{4}\right)_{2} \mathrm{SO}_{4}$ and $0.1 \%(\mathrm{w} / \mathrm{v})$ each of unlabelled $\mathrm{L}$-arginine and DL-methionine. The filters were mounted in planchets and counted with a Nuclear Chicago windowless gas flow counter.

\section{RESULTS}

Ampicillin-induced lysis was studied with Escherichia coli $\mathrm{k} 12$, strain x 5, with a generation time of about $35 \mathrm{~min}$. in broth medium at $37^{\circ}$. An exponentially growing culture was diluted at zero time into three parts with fresh medium. To the first and second parts, ampicillin (SPC 270) was added to final concentrations of $4 \cdot 2$ and $8 \cdot 3 \mu \mathrm{g} . / \mathrm{ml}$., respectively. The third portion was the control. Growth was continued at $37^{\circ}$ and the optical density followed for about two generations. Figure 1 shows that, in the cultures with ampicillin, the cell mass continued to increase, for high concentrations of penicillin, at a rate somewhat lower than the normal growth, and that lysis started rather abruptly. The highest points of the curves for penicillin cultures (filled symbols in Fig. 1) have been defined as 'the moment when lysis starts', and the 'time to lysis' as the period between the addition of penicillin and 'the moment when lysis starts'. The 'time to lysis' can be expressed in terms of normal generations and the 'lysis ratio' is in the following defined as:

$$
\text { lysis ratio }=\frac{\text { generation time of control culture (min.) }}{\text { time to lysis of penicillin culture (min.) }}
$$

Figure 1 shows that the lysis ratio varied with the penicillin concentration and with $4 \cdot 2$ and $8 \cdot 3 \mu \mathrm{g}$. ampicillin (SPC 270 ) $/ \mathrm{ml}$. the lysis ratios obtained were 0.77 and $1 \cdot 0$, respectively. The penicillin dependence of the lysis ratio was compared for three forms of ampicillin, pure $\mathrm{D}$ - and $\mathrm{L}$ - isomers and a mixture of about $60 \% \mathrm{D}$ - and $40 \% \mathrm{~L}$-isomer (SPC 270). The results are given in Fig. 2 and show that the D-isomer was more active than the L-isomer and that the 6:4 mixture (SPC 270) was only slightly less active than the D-isomer. Drs B. Sjöberg and B. Ekström have recently found that the half-life at $37^{\circ}$ and $\mathrm{pH} 7$ is about $100 \mathrm{hr}$. for the $\mathrm{D}$-isomer and $15 \mathrm{hr}$. for the L-isomer, and that these times are significantly influenced by the composition of the medium. This difference in stability would affect determinations of the antibiotic activity by viable counts or minimum inhibitory concentration (MIC). However, our determinations of the lysis ratios were completed within a few hours and 
a difference in stability cannot explain the differences in the lysis ratios for the D- and L-isomers.

The experimental error in the determination of the lysis ratio may well be of the order of $10 \%$, and, for ratios higher than 2, even greater. Determinations of curves like those in Fig. 2 are, however, fairly reproducible when 6 to 8 points are taken in each experiment. The extrapolated penicillin concentration which corresponds to lysis in one generation (LIOG value) is used in the sequel as a characteristic of different penicillin derivatives as well as of bacterial strains. The LroG values obtained from Fig. 2 are for the D-isomer $6 \mu \mathrm{g}$. $/ \mathrm{ml}$, , for the $\mathrm{L}$-isomer $22 \mu \mathrm{g} . / \mathrm{ml}$. and for SPC $8 \mu \mathrm{g} . / \mathrm{ml}$.

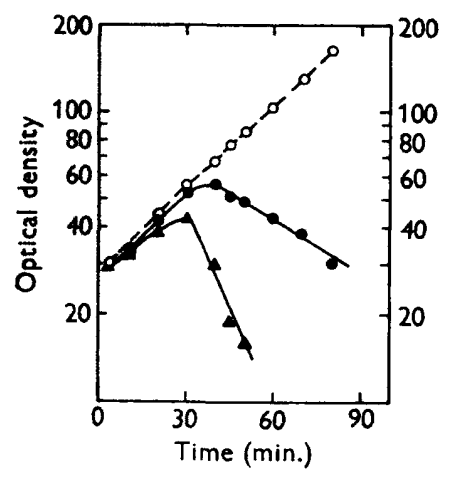

Fig. 1

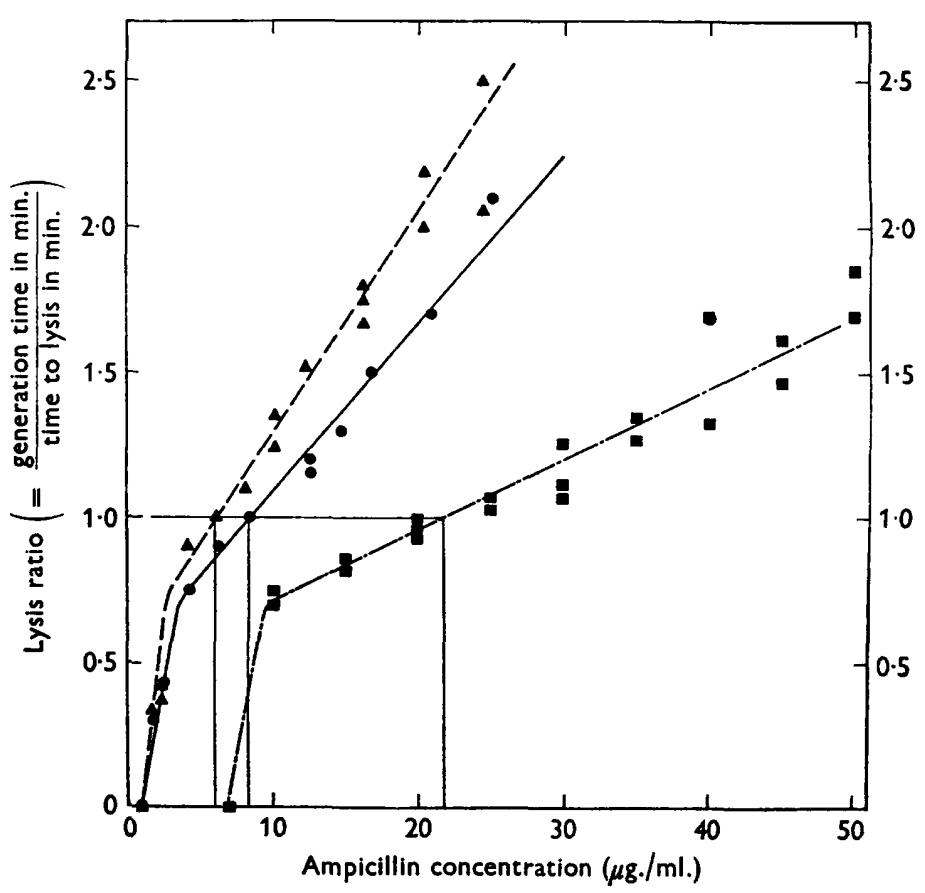

Fig. 2

Fig. 1. Growth curves for three cultures obtained by dilution of an exponentially

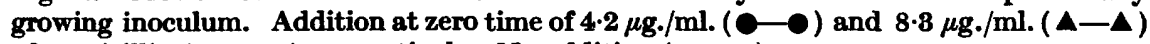
of ampicillin (SPC 270), respectively. No addition (O- $-\mathrm{O})$.

Fig. 2. Lysis rates for different concentrations of three forms of ampicillin ( $\alpha$-aminobenzyl penicillin). Pure D-isomer $(\Delta--\Delta)$, pure $L$-isomer $(\square--\square)$, and the mixture $(6: 4)$ 8PC $270(-)$ ). The wog values are defined as concentrations giving lysis ratio $=1$.

\section{Independence of lysis rate and concentration of organisms}

A well-known characteristic of penicillin $G$ (see the review by Cooper, 1956) is that for non-penicillinase-producing strains the antibiotic effect is independent of the size of the inoculum. This has been confirmed with ampicillin. The Klett photometer used only permitted the measurement of growth curves with a threefold difference in size of inoculum; under these conditions the time to lysis was found to vary by only $0 \cdot 1$ generation, which was considered to be within the experimental error. It was found, however, that growth above $10^{5}$ organisms $/ \mathrm{ml}$. could be recorded 
in a minimal medium with carrier-free radioactive sulphate and ${ }^{14} \mathrm{C}$ labelled arginine and methionine, simply by following the incorporated radioactivity collected on a bacterial filter. Figure 3 shows the results of such an experiment where a dilute culture after $3 \mathrm{hr}$. was divided into two parts: to one was added $6 \cdot 2 \mu \mathrm{g}$. ampicillin (SPC 270)/ml., the other portion being kept as control. As reference, viable counts were made at the two points indicated in the figure. It can be seen that the incorporation continued in the penicillin culture for about $1 \mathrm{hr}$. and that the radioactivity on the filter then decreased for the next $2 \mathrm{hr}$. The generation time for the control in this experiment was $78 \mathrm{~min}$. and the lysis ratio recorded was 0.86 , which is in good agreement with the value 0.79 obtained with about $10^{8}$ organisms $/ \mathrm{ml}$. The similarity between the curves obtained by the incorporation of isotopes and the reading on the Klett photometer is also a control on the assumption that the optical density was directly related to cell mass.

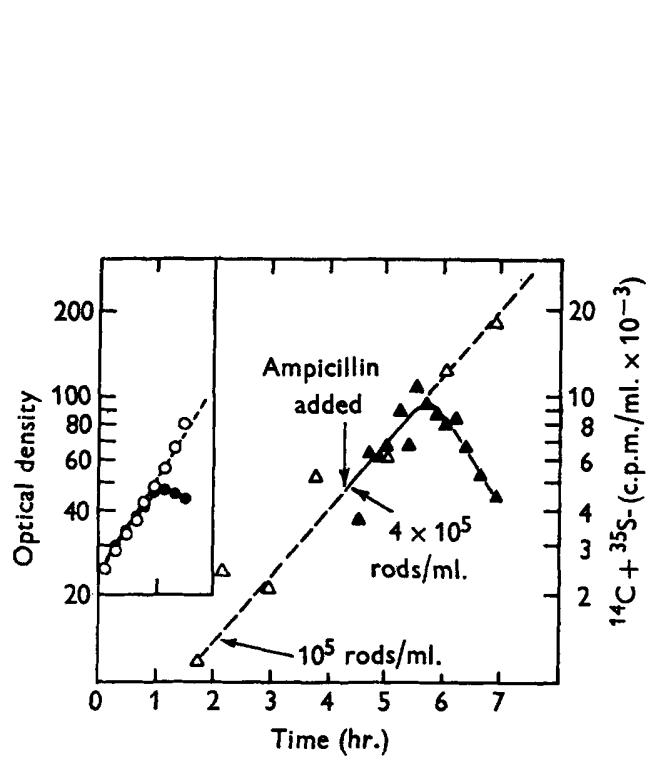

Fig. 3

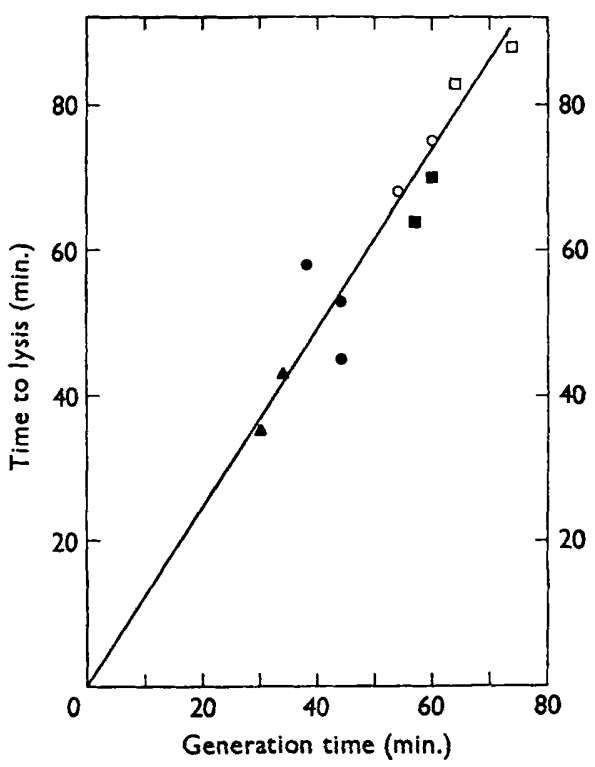

Fig. 4

Fig. 3. Growth curve for a dilute culture followed by recording the radioactivity collected on a bacterial filter $(\Delta--\Delta)$. Minimal medium with carrier free ${ }^{35} S$ sulphate and ${ }^{14} \mathrm{C}$ arginine and ${ }^{14} \mathrm{C}$ methionine. Arrows indicate time of viable counts and addition of $6.2 \mu \mathrm{g} . / \mathrm{ml}$. of ampicillin (SPC 270) to half of the culture ( $\Delta-\Delta$ ). Left part gives a control experiment with about $10^{8}$ rods $/ \mathrm{ml}$.

Fig. 4. The time to lysis for different generation times obtained during balanced growth in different media. Nutrient broth + glucose ( $\Delta$ ); casamino acids + glucose $(O)$; arginine + methionine + glucose $(\square)$; casamino acids + glycerol $(O)$; arginine + methionine+ glycerol ( $\square$ ); ampicillin (SPC 270) conc. $6 \cdot 2 \mu \mathrm{g} . / \mathrm{ml}$.

\section{The influence of the medium on the time to lysis}

Todd (1945) showed that for Gram-positive bacteria 'the most rapid lysis occurs with organisms at the maximal rate of multiplication', but he could not demonstrate this for 'Bacillus coli'. Since then some conflicting data have been reported (see review by Hugo \& Russell, 1961), but it is a general rule that penicillins act only 
on growing organisms. We studied the time to lysis for Escherichia coli strain $\mathbf{x} 5$ in five different media which gave more than a twofold difference in growth rates. The results obtained with 6.2 $\mu$ g. ampicillin (SPC 270)/ml. are given in Fig. 4 and show that the time to lysis was directly proportional to the generation time. This means that when data for the lysis rates are expressed in terms of generations, they are independent of the growth rate and this makes the LIOG value a more meaningful parameter.

Prestidge \& Pardee (1957) showed with Escherichia coli that inhibition of protein synthesis by chloramphenicol stopped penicillin action. A change from a rich medium to minimal medium is known to give a lag in growth during which time some protein synthesis occurs (Kjeldgaard, Maaløe \& Schachter, 1958; Neidhardt \& Magasanik, 1960). In the following experiment we used this lag to study ampicillin action during limited protein synthesis. A culture of $E$. coli strain $\times 5$ (100 ml.) was grown in nutrient glucose medium, centrifuged and the organisms washed once with an equal volume of medium $\mathbf{E}$ and then resuspended in minimal medium with $6 \cdot 2 \mu \mathrm{g}$. ampicillin (SPC 270)/ml. Aeration and incubation at $37^{\circ}$ were continued and after 15 and $75 \mathrm{~min}$. two $18 \mathrm{ml}$. samples were transferred to flasks with $2 \mathrm{ml}$. of $8 \%$ nutrient broth containing 6.2 $\mu \mathrm{g}$. ampicillin $/ \mathrm{ml}$. Figure 5 shows that no lysis occurred during the lag phase, but that lysis started a certain time after growth was resumed. The time to lysis was $54 \mathrm{~min}$. in the first flask (curve $A$ ) and in the second one $96 \mathrm{~min}$. (curve $B$ ). Thus some destruction of penicillin would seem to have occurred during this lag phase. It has only been possible to demonstrate this time effect with ampicillin concentrations lower than the LIOG value, a fact which is consistent with the break in the curve for the concentration dependence (see Fig. 2).

\section{Exposure to penicillin for limited times}

An excess of penicillinase (Methods) can in a few seconds inactivate all the penicillin of a culture and the enzyme is thus a suitable tool for obtaining pulse doses of penicillin. An exponentially growing culture was inoculated at zero time into several flasks of media containing $6 \cdot 2 \mu \mathrm{g}$. ampicillin (SPC 270$) / \mathrm{ml}$. Incubation was continued and penicillinase was added at different times to a final concentration of 500 units $/ \mathrm{ml}$. When penicillinase was added within 0.8 generation growth continued in a normal way. When it was added after 1 generation penicillinase almost completely prevented lysis and the growth curve showed only an inflexion point. When the penicillinase treatment was replaced by centrifugation, and washing and resuspending the organisms in fresh medium without ampicillin the same result was obtained. Figure $6 a$ shows the Klett photometer readings from an experiment in which an exponentially growing culture of $E$. coli strain $\times 5$ was divided into three portions: one portion served as control, and the two others received $6 \cdot 2 \mu \mathrm{g}$. ampicillin (SPC 270)/ml. at zero time. Growth conditions were continued and, after 1.3 generations, one of the ampicillin cultures received 500 units penicillinase $/ \mathrm{ml}$. About $15 \%$ of the organisms lysed in this culture before growth was resumed. The culture which only received ampicillin gave almost complete lysis. Figure $6 b$ gives viable counts for the same three cultures. The ampicillin culture, which received penicillinase at the start of lysis, lost $88 \%$ of its viable units in $75 \mathrm{~min}$. but recovered the starting population of viable organisms about $60 \mathrm{~min}$. later. This result is believed to come from two superimposed effects. First, a fraction of the organisms 


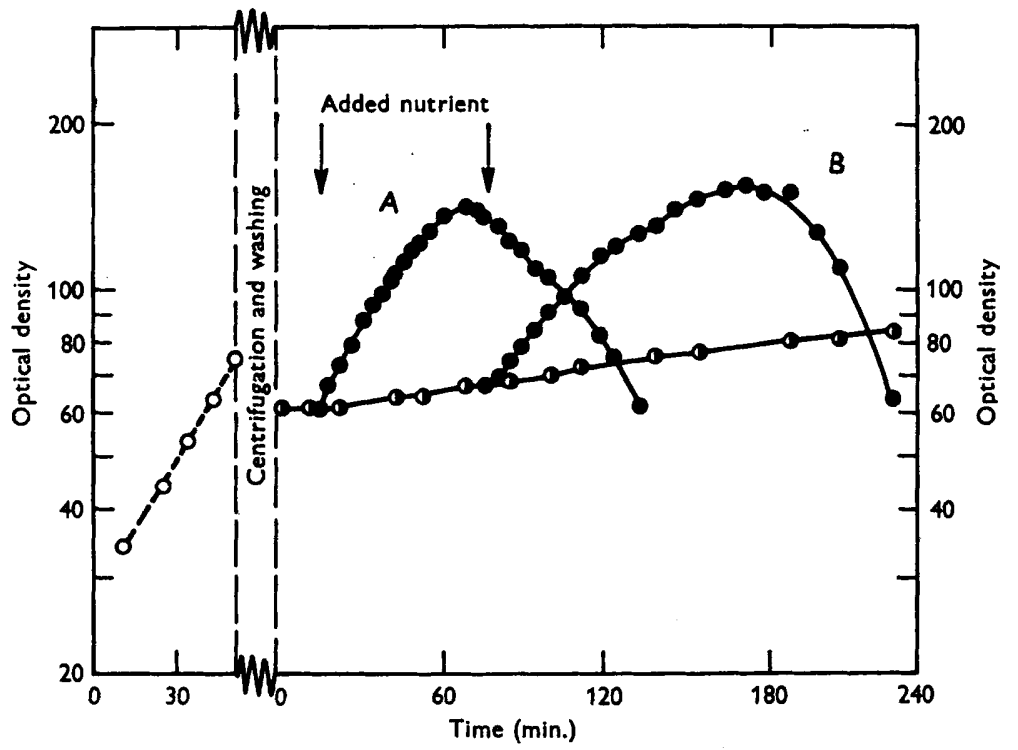

Fig. 5. Ampicillin action during lag phase produced by a shift from rich to minimal medium. Growth in nutrient glucose $\left(\mathrm{O}^{-}-\mathrm{O}\right)$; washed cells suspended in minimal medium with $6 \cdot 2 \mu \mathrm{g} . / \mathrm{ml}$. of ampicillin (SPC 270) $(0-0)$; aliquots of culture to which nutrient was added at the times indicated by the arrows $(0-0)$.
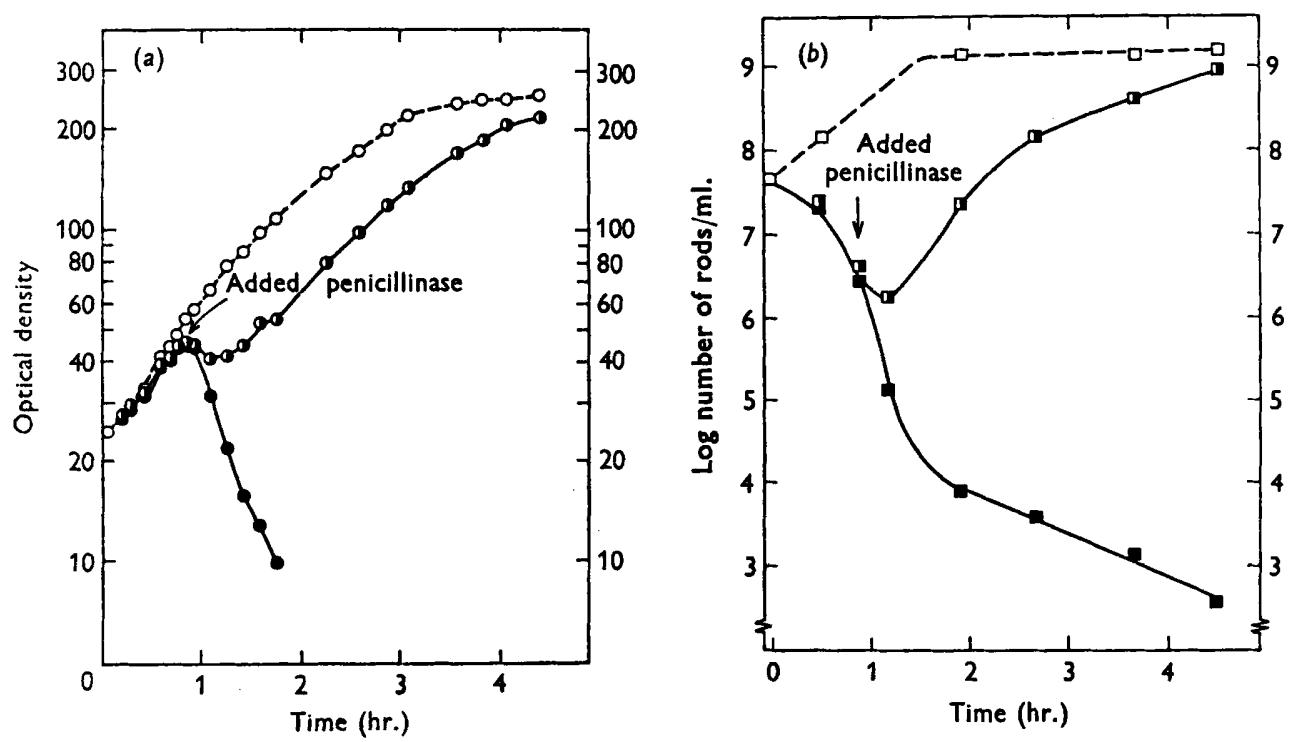

Fig. 6. Influence of penicillinase added to a culture growing in the presence of $6 \cdot 2 \mu \mathrm{g} . / \mathrm{ml}$. of ampicillin (SPC 270). Part (a) gives optical densities (circles) and part (b) viable counts (squares) for the same three cultures. Ampicillin added at zero time (filled symbols). Ampicilin added at zero time and penicillinase at time indicated by arrows (half-filled symbols). No additions (open symbols). 
is likely to be killed during the viable count determination, which makes the death rate seem faster than it really is. Secondly, penicillin is known to give rise to large elongated organisms (see review by Rogers, 1962) and, if such organisms started to divide, the number of viable units might increase more rapidly than in normal growth.

\section{Mutants resistant to ampicillin}

Several penicillin-resistant mutants were derived from Escherichia coli strain $\mathbf{x} 5$. They were isolated by the spreading of about $10^{\circ}$ organisms on nutrient agar plates containing different concentrations of the $D$-isomer of ampicillin. The spontaneous frequency of mutants resistant to $1 \mu \mathrm{g}$. ampicillin $/ \mathrm{ml}$. was estimated for $E$. coli strain $x 5$ to be about 4 in $10^{8}$ organisms and a similar figure was obtained for an $E$. coli strain B. Some of the mutants were characterized by their LIOG and MIC values, and by their growth on plates with ampicillin; the results are summarized in Table 1. For three mutants, LIOG values were determined for ampicillin and for penicillin G; Table 1 shows that the ratio of the LIOG values changed. Preliminary investigations have shown no penicillinase in the wild type but some in the mutants. A further study of penicillin-resistant mutants is planned.

Table 1. Characterization of some penicillin-resistant mutants of Escherichia coli $K 12$ strain $x 5$

\begin{tabular}{|c|c|c|c|c|c|c|c|}
\hline Strain & $\begin{array}{c}\text { Parent } \\
\text { strain }\end{array}$ & $\begin{array}{c}\text { Ampicillin } \\
\text { during iso- } \\
\text { lation } \\
(\mu \mathrm{g} . / \mathrm{ml} .)\end{array}$ & $\begin{array}{l}\text { Limits of } \\
\text { ampicillin } \\
\text { on plates } \\
(\mu \mathrm{g} . / \mathrm{ml} .)\end{array}$ & $\begin{array}{c}\text { MIC } \\
\text { ampicillin } \\
(24 \mathrm{hr} .) \\
(\mu \mathrm{g} . / \mathrm{ml} .)\end{array}$ & $\begin{array}{c}\text { LroG } \\
\text { ampicillin } \\
(\mu \mathrm{g} . / \mathrm{ml} .)\end{array}$ & $\begin{array}{c}\text { LIOG } \\
\text { penicillin } G \\
(\mu \mathrm{g} . / \mathrm{ml} .)\end{array}$ & $\begin{array}{c}\begin{array}{c}\text { LIOG } \\
\text { penicillin G }\end{array} \\
\text { ITOG } \\
\text { ampicillin }\end{array}$ \\
\hline $\mathbf{x} 5$ & 一 & 一 & $<1$ & 4 & 6 & $\mathbf{5 4}$ & $9 \cdot 0$ \\
\hline$\times 5-1$ & $\mathbf{x} 5$ & 1 & $4<8$ & 8 & 19 & - & - \\
\hline$x$ 5-4 & $\mathbf{x} 5$ & $\mathbf{1}$ & $4<8$ & 8 & 19 & - & - \\
\hline$\times 5-5$ & x 5-1 & 5 & $4<8$ & 8 & 19 & 110 & $5 \cdot 8$ \\
\hline$\times 5-8$ & $\times 5-5$ & 50 & $120<240$ & 64 & 180 & 870 & 4.8 \\
\hline
\end{tabular}

Strain $\times$ 5-8 was obtained after ultra-violet radiation, other mutants are spontaneous. The ampicillin used during isolation was pure $\mathrm{D}$-isomer, while other experiments were done with SPC 270.

\section{Influence of different side chains on the penicillin}

Most penicillins so far have been found rather inactive against Gram-negative bacteria and relatively few comparisons have therefore been published about the action of different penicillins on Escherichia coli; Hugo \& Russell (1960) and Russell (1962) reported comparisons of some penicillin derivatives. Rogers \& Mandelstam (1962) studied inhibition of mucopeptide formation in $E$. coli and found ampicillin to be about 10 times more active than penicillin $G$. We have compared the lytic activity (estimated as LIOG values) of several penicillin derivatives, with strain $\mathrm{x} 5$ as test organism; the results are given in Table 2. They show that the side chain of the penicillin molecule has a profound influence on the lysis rate of $\boldsymbol{E}$. coli. This is exemplified by, for instance, the two chloro-substituted isomers of ampicillin, which differ by a factor of 4 , the $m$ form being more active than the $p$ form. A comparison of the structures of the side chains shows that the substituents around the $\alpha$-carbon atom are of importance. The most striking differences were recorded when a hydrogen in penicillin $\mathbf{G}$ was substituted with a methyl group or an amino group (compare 
compounds nos. 1-3, 8 and 9). The fact that the D-isomer of ampicillin is almost 4 times more active than the L-isomer (see Fig. 2) shows that the steric configuration around the $\alpha$-carbon atom is also of importance. It may be noted that penicillins nos. 12 and 13, which are resistant to penicillinase (Doyle et al. 1961) and

Table 2. Penicillin derivatives tested on Escherichia coli $K 12$ strain $x 5$

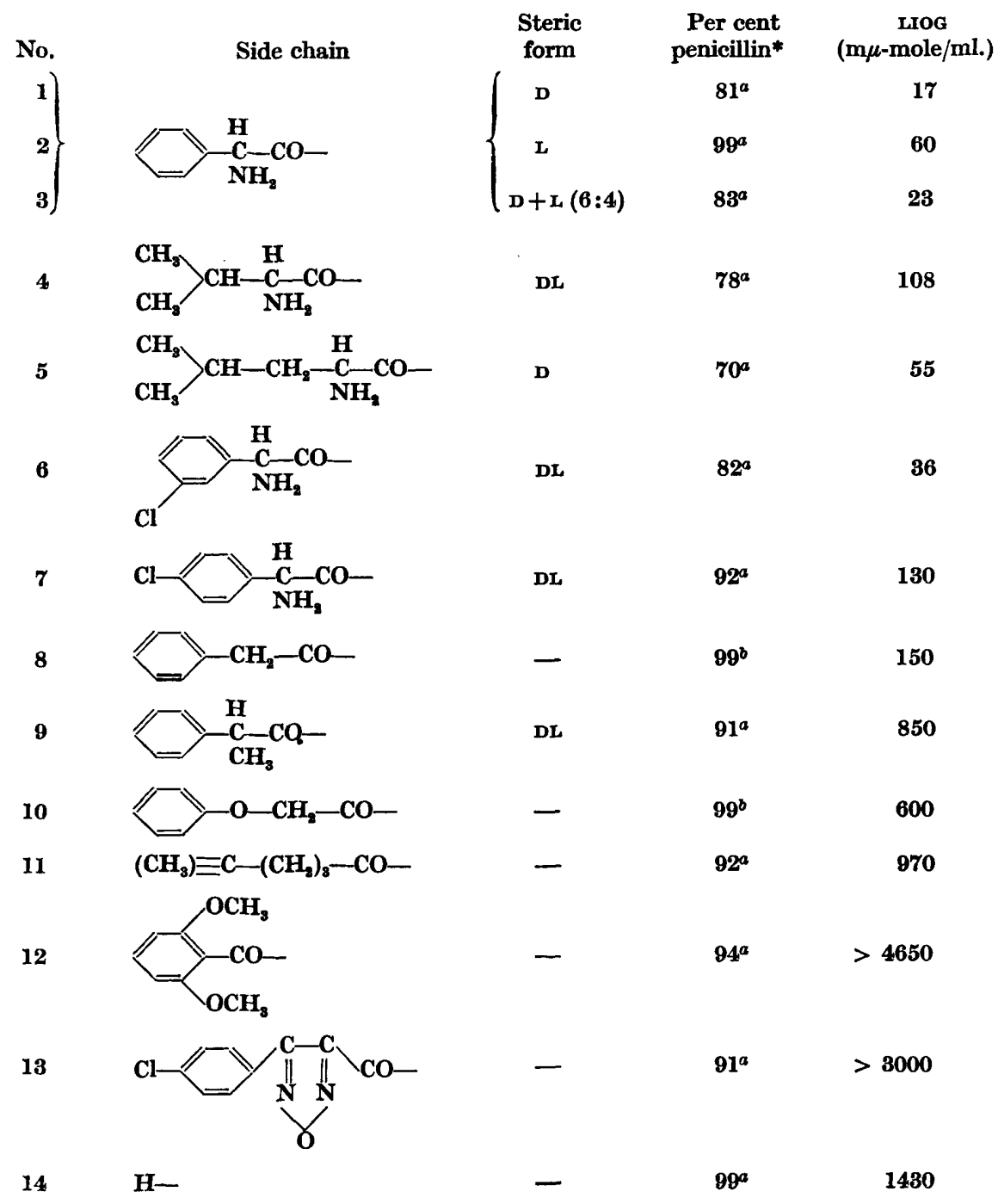

* These data were obtained from Dr Sjöberg, Astra. $a$ refers to analysis by differential alkalimetric titration; $b$ refers to analysis by the hydroxylamine method. The remaining percentages are in most of the penicillins accounted for by moisture.

relatively active against certain Gram-positive bacteria, possess almost no lytic activity for $E$. coli. Cephalosporin $\mathbf{N}$ was not available to us in a sufficiently pure form.

We tested certain amino acids (whose residues are side chains in some of the 
penicillins) for their effect on the time to lysis with 6-aminopenicillanic acid as well as ampicillin. The results of such an experiment with 6-aminopenicillanic acid and D-phenylglycine is shown in Fig. 7 ; synergistic effects were found also with valine +6-aminopenicillanic acid. Relatively high concentrations of amino acids were needed, but no influence on the growth curve was obtained in control experiments with the same concentration of amino acid only (compare open circles and open triangles in Fig. 7). The fact that phenylglycine gave synergistic effects with 6-amino penicillanic acid and with ampicillin is most easily explained as a limited hydrolysis and resynthesis of ampicillin, reactions which are both known to occur in Escherichia coli.

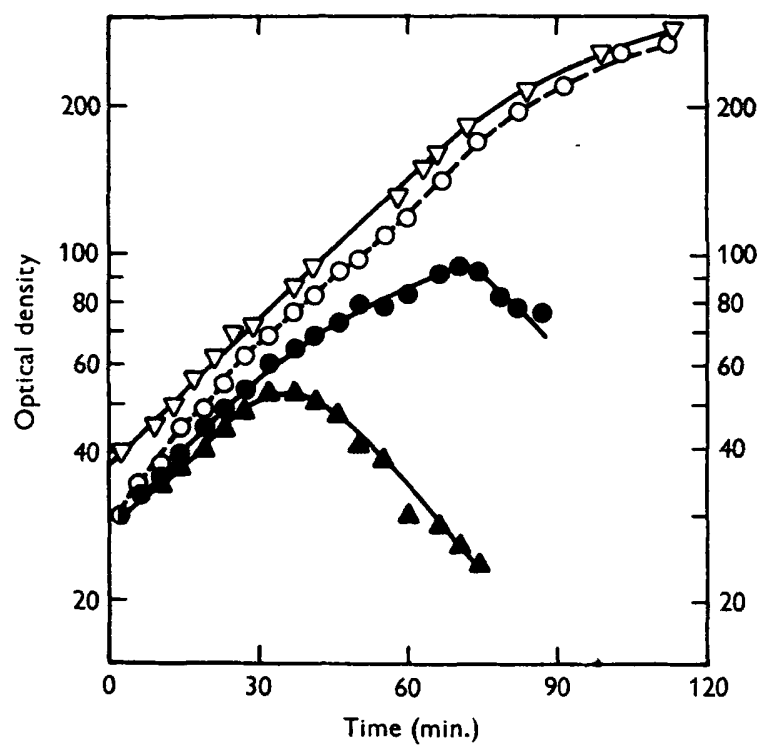

Fig. 7. Growth curves with 6-aminopenicillanic acid $(100 \mu \mathrm{g} . / \mathrm{ml}$.) (O-O); 6-aminopenicillanic acid $(100 \mu \mathrm{g} . / \mathrm{ml})+.\mathrm{D}$-phenyl glycine $(350 \mu \mathrm{g} . / \mathrm{ml}$.) $(\Delta-\Delta)$; D-phenyl glycine $(850 \mu \mathrm{g} . / \mathrm{ml}).(\nabla-\nabla)$; and no addition $(\mathrm{O}-\mathrm{O})$.

\section{DISCUSSION}

In the extensive literature on penicillin action (see review by Hugo \& Russell, 1961) the methods of observation normally used are measurements of viable count, which takes $48 \mathrm{hr}$., and minimal inhibitory concentration (MIC), which takes $24 \mathrm{hr}$. These times correspond, with Escherichia coli strain X5, to about 72 and 36 generations, respectively; and the two methods have a disadvantage in common in that they record the result of penicillin action rather than the course of the reaction. Prestidge \& Pardee (1957) observed that bacteria treated with penicillin excreted a nucleotide-like material which can be used for recording of penicillin action on the bacteria. Optical methods were used by Liebermeister \& Kellenberger (1956) for the study of penicillin action on Proteus vulgaris and by Fukasawa \& Nikaido (1961) for a galactose-induced lysis of certain mutants of Salmonella enteritidis. The optical method of studying penicillin action would seem to have the following advantages: (1) To permit a relatively accurate recording of the time to lysis which is a basis for 
an analysis of penicillin action. (2) To permit comparative investigations of penicillin derivatives with relatively short half-lives, as exemplified in the study of the $\mathrm{D}$ - and the $\mathrm{L}$ - isomers of ampicillin. (3) To permit a rapid recording of the penicillin sensitivity of a bacterial strain (expressed as LIOG value), information which sometimes is of clinical interest, and where the time saved (as compared with a determination of M.I.C.) can be of importance. The penicillin dependence of the lysis ratio is also a useful method for the characterization of penicillin-resistant mutants.

The most commonly accepted explanation for penicillin action (see reviews by Strominger, 1960; Rogers, 1962) is that the compound blocks cell-wall synthesis by inhibiting an enzyme which joins the Park \& Strominger mucopeptide with the acceptor of the wall structure (Park \& Strominger, 1957). Protein synthesis and presumably a large part of the cell metabolism is, however, unaffected by penicillin (Mandelstam \& Rogers, 1959; Hancock \& Park, 1958) and as the result of continued increase in cell mass the osmotic pressure is increased until lysis occurs. Conflicting statements have previously been made about penicillin action on RNA metabolism. However, we have found that the activity of soluble RNA seems to be affected (to be published) and this is reasonable, since uridylic and cytidylic compounds accumulate during penicillin action (Strominger, 1960; Saukkonen, 1961) and the re-utilization of these mucleotides may thus be blocked. Several investigators (Prestidge \& Pardee, 1957; Hugo \& Russell, 1961) have suggested that penicillin may have an additional action beside that of the inhibition of cell-wall synthesis.

The results of our work suggest that a mechanism for the action of penicillin on Escherichia coli would be consistent with the following three observations: (1) Within a wide range penicillin action is independent of the number of organisms in the culture. (This implies lack of penicillinase or any other enzyme which can cause inactivation of penicillin.) (2) The time to lysis is inversely proportional to the growth rate under balanced growth at $37^{\circ}$. (3) The lysis ratio has a characteristic dependence on the penicillin concentration, and is linear over a certain range. The first of these observations has been interpreted to mean that each rod may be considered as a separate unit and that the amount of penicillin possibly consumed is negligible for the concentration dependence observed during balanced growth.

The second relation, that there is a direct correlation between the growth rate and the time to lysis is consistent with the well-known observation that penicillin only kills growing organisms. In spite of this fact most previous workers have described the course of penicillin action only in time (minutes) and not in terms of generations. By using radioactive penicillin with Gram-positive organisms Cooper, Clowes \& Rowley (1954) showed the specific binding of penicillin and they also introduced the concept of the penicillin-binding component (PBC). The biochemical nature of the PBC is yet unknown, but Cooper (1956) seemed to visualize the component as a membrane-bound enzyme; this hypothesis was further discussed by Pollock (1957). It is reasonable to assume that organisms with higher growth rate, in general, would have a higher rate of synthesis of their essential enzymes. Thus, if PBC were an enzyme and if penicillin action were the inactivation of this enzyme, one would expect a higher growth rate to decrease the sensitivity to penicillin; this is contrary to what we have observed. Two alternative explanations seem, however, to account for the fact that the time to lysis decreases with increasing growth rate. (a) PBC might 
be an enzyme which is not inactivated by penicillin but which converts penicillin into another product which in turn is the real toxic factor for the bacteria. If so, then a higher rate of synthesis of $\mathrm{PBC}$ might lead to a higher concentration of the real toxic factor. (b) PBC might be an intermediate $B$ in a pathway for the synthesis of cell-wall components. It would normally react with compound $\mathrm{A}-\mathrm{X}$ to give the essential products $\mathbf{B}-\mathbf{X}$ and $\mathbf{A}$, and the absence of these compounds would cause lysis. This is not an unreasonable assumption, since it is known that starvation for lysine or diaminopimelic acid causes lysis (Meadow, Hoare \& Work, 1957). In the presence of penicillin, intermediate $B$ would instead react with penicilln (Pen) and give the products $B-Y$ and $D$ :

$$
\begin{gathered}
\mathbf{A}-\mathbf{X}+\mathbf{B} \stackrel{\mathbf{R}}{\longrightarrow} \mathbf{B}-\mathbf{X}+\mathbf{A}, \\
\mathbf{P e n}+\mathbf{B} \stackrel{\mathbf{E}}{\longrightarrow} \mathbf{B}-\mathbf{Y}+\mathbf{D} .
\end{gathered}
$$

If compound $B$ were such an intermediate it might well be that its intracellular concentration would be inversively proportional to the growth rate. Thus, if the absence of B-X and A produced lysis, such a system would account for the fact that the lysis rate is proportional to the growth rate. The time required by the organisms to exhaust their steady state concentration of intermediate $B$ would be recorded as the time to lysis. The penicillin dependence observed would be consistent with arguments about the expected influence that penicillin concentration and pulse doses might have on the rates of reactions (1) and (2).

It was pointed out by Cooper (1956) that the penicillin side chain seems to be of relatively little importance for the activity against Gram-positive organisms. Our results in Table 2 show that the side chain has a marked influence on penicillin action with strain $x 5$ of Escherichia coli. A comparison of the LIOG values expressed on molar basis for compounds no. 12-14 show that these penicillin derivatives have a lower activity than 6-aminopenicillanic acid (no. 14) and that bulky and probably unbiological side chains can give lower activity than absence of side chain. Table 2 also shows that amino-acyl side chains in general give highly active penicillins. Since methyl and amino groups are of a similar size it would seem difficult to explain the differences between compounds nos. 3, 8 and 9 in Table 2 in terms of steric hindrance. The drastic influence of the side chain may, however, be accounted for by assuming an interaction, possibly a hydrogen bond, between certain groups on the $\alpha$-carbon atom and the $\beta$-lactam ring.

An additional hypothesis seems to be consistent with our results, namely that the side chain could be transferred to an acceptor by a transpeptidase reaction. The side chains of penicillins nos. 12 and 13 would both be expected to provide steric hindrance for such a reaction and this might explain why these compounds are almost inactive. A transpeptidase reaction may be reasonable in view of the fact that the cell wall of Escherichia coli contains at least eleven common amino acids (Salton, 1960 b; Work, 1961). Some strains of $\boldsymbol{E}$. coli are also known to possess an enzyme which can hydrolyse the bond between the side chain and the 6-aminopenicillanic acid (English, McBride \& Huang, 1960).

The reactions discussed above are only alternative ways to account for the action of penicillin. The model is speculative but may be useful in the number of further experiments which it can suggest, especially through the use of different labelled penicillins. It should be emphasized that the discussion concerns Escherichia coli. 
Rogers \& Mandelstam (1962) pointed out that the concentration of penicillin $G$ required to inhibit mucopeptide synthesis is about 500 times higher for $E$. coli than for a sensitive strain of Staphylococcus. This drastic difference as well as recent comparisons of different penicillins on other strains (Knox \& Smith, 1961; Rogers \& Jeljaszewicz, 1961) may indicate that parts of the mechanism have species specificity.

We have had the advantage of discussing our results with several colleagues and would especially like to thank Drs B. Sjöberg and G. Bertani for helpful suggestions and criticism. We are also indebted to Dr H. J. Rogers for valuable discussions and for making two manuscripts under publication available to us. The work was supported by Astra Co. and by U.S. Public Health Service, grant no. RG-7576. K.G.E. has been holder of a Sven and Lilly Lawski fellowship.

\section{REFERENCES}

Abraham, E. P. \& Newton, G. G. F. (1961). New penicillins, cephalosporin C and penicillinase. Endeavour, 20, 92.

Batchelor, F. R., Doyle, F. P., Nayler, J. H. C. \& Rournson, G. N. (1959). Synthesis of penicillin: 6-aminopenicillanic acid in penicillin fermentations. Nature, Lond. 183, 257.

Cooper, P. D., Clowes, R. C. \& Rowley, D. (1954). A note on the use of radioactive penicillin. J. gen. Microbiol. 10, 246.

CoOper, P. D. (1956). Site of action of radiopenicillin. Bact. Rev. 20, 28.

Doyle, F. P., Long, A. A. W., Nayler, J. H. C. \& Stove, E. R. (1961). New penicillins stable towards both acid and penicillinase. Nature, Lond. $192,1183$.

English, A. R., McBride, T. J. \& Huang, H. T. (1960). Microbial resistance to penicillin as related to penicillinase or penicillin acylase activity. Proc. Soc. exp. Biol., N.Y. 104, 547.

Fukasawa, T. \& Nikamo, H. (1961). Galactose-sensitive mutants of Salmonella. II. Bacteriolysis induced by galactose. Biochim. biophys. Acta, 48, 470.

Hancock, R. \& Park, J. T. (1958). Cell-wall synthesis by Staphylococcus aureus in the presence of chloramphenicol. Nature, Lond. 181, 1050.

Hugo, W. B. \& Russell, A. D. (1960). Action of 6-aminopenicillanic acid on Gramnegative bacteria. Nature, Lond. $188,875$.

Hugo, W. B. \& Russell, A. D. (1961). Review article. The mode of action of penicillin. J. Pharm., Lond., 13, 705.

KueldgaARd, N. O., MaAløe, O. \& Schaechter, M. (1958). The transition between different physiological states during balanced growth of Salmonella typhimurium. J. gen. Microbiol. 19, 607.

Knox, R. \& Smith, J. T. (1961). The nature of penicillin resistance in staphylococci. Lancet, ii, 520.

LEDERBERG, J. (1950). Isolation and characterization of biochemical mutants of bacteria. Meth. med. Res. 3, 5.

Levy G. B. (1950). A unit of penicillase. Nature, Lond. 166, 740.

Liebermeister, K. \& Kellenberger, E. (1956). Studien zur L-Form der Bakterien. Die Umwandlung der bazillären in die globuläre Zellform bei Proteus unter Einfluss von Penicillin. Naturforschung, $\mathrm{II} b, 200$.

Mandelstam, J. \& Rogers, H. J. (1959). The incorporation of amino acids into the cellwall mucopeptide of staphylococci and the effect of antibiotics on the process. Biochem. J. 72, 654 .

Meadow, P., Hoare, D. S. \& Work, E. (1957). Interrelationship between lysine and $\alpha$-, $\epsilon$-diamino pimelic acid and their derivatives and analogues in mutants of Escherichia coli. Biochem. J. 66, 270. 
Nemphardt, F. C. \& Magasanik, E. (1960). Studies on the role of ribonucleic acid in the growth of bacteria. Biochim. biophys. Acta, 42, 99.

Novelu, G. D. (1960). Protein synthesis in microorganisms. Annu. Rev. Microbiol. 14, 65.

Park, J. T. \& Strominger, J. L. (1957). Mode of action of penicillin. Biochemical basis for the mechanism of action of penicillin and for its selective toxicity. Science, 125, 99.

PoLLOCK, M. R. (1957). The activity and specificity of inducers of penicillinase production in Bacillus cereus, strain NRRL 569. Biochem. J. 66, 419.

Pollock, M. R. (1959). Induced formation of enzymes. In The Enzymes, Ed. by P. D. Boyer, H. Lardy \& K. Myrbäck. Vol. 1, p. 619. New York: Academic Press.

Prestidge, L. S. \& Pardee, A. B. (1857). Induction of bacterial lysis by penicillin. J. Bact. 74, 48.

Roberts, R. B., Abelson, P. H., Cowie, D. B., Bolton, E. T. \& Britten, R. J. (1957). Studies of biosynthesis in Escherichia coli. Washington, D.C.: Publ. Carneg. Instn. No. 607.

Rogers, H. J. \& JeLJaszewicz, J. (1961). Inhibition of the biosynthesis of cell-wall mucopeptides by the penicillins. A study of penicillin-sensitive and penicillin-resistant strains of Staphylococcus aureus. Biochem. J. 81, 576 .

Rogers, H. J. (1962). Mode of action of the penicillins. In Resistance of Bacteria to the Penicillins. CIBA Foundation Study Group, No. 13, p. 25. London : J. and A. Churchill Ltd.

Rogers, H. J. \& Mandelstam, J. (1962). Inhibition of cell wall mucopeptide formation in Escherichia coli by benzylpenicillin and $6[\mathrm{D}(-)-\alpha$-amino-phenylacetamido] penicillanic acid ('ampicillin'). Biochem. J. 84, 299.

Rolinson, G. N. \& Stevens, S. (1961). Microbiological studies on a new broad-spectrum penicillin, 'Penbritin'. British med. J. (22/7), 191.

Russell, A. D. (1962). A note on the activity of six penicillins against Escherichia coli. J. Pharm., Lond. 14, 390.

Salton, M. R. J. (1960a). Microbial Cell Walls. New York and London: John Wiley and Sons, Inc.

Salton, M. R. J. (1960b). Surface layers of the bacterial cell. In The Bacteria, Ed. by I. C. Gunsalus \& R. Y. Stainer, Vol. 1, p. 123. New York: Academic Press.

SaUkKonen, J. J. (1961). Acid-soluble nucleotides of Staphylococcus aureus: massive accumulation of a derivative of cytidine diphosphate in the presence of penicillin. Nature, Lond. 192, 816.

Strominger, J. L. (1960). Mononucleotide acid anhydrides and related compounds as intermediates in metabolic reactions. Physiol. Rev. 40, 55.

ToDd, E. M. (1945). Bacteriolytic action of penicillin. Lancet, i, 74.

Vogel, H. J. \& BonNer, D. M. (1956). Acetylornithinase of Escherichia coli: partial purification and some properties. J. biol. Chem. 218, 97.

Work, E. (1961). The mucopeptides of bacterial cell walls. A review. J. gen. Microbiol. 25, 167 . 